\title{
EFEKTIVITAS BENTUK FISIK RANSUM DAN POD KAKAO (Theobrama cacao L.) YANG DIFERMENTASI DENGAN Aspergillus niger TERHADAP KARKAS KELINCI REX LEPAS SAPIH
}

\author{
(Effectiveness of Physical Form Rations and Cocoa Pod (Theobrama cacao L.) Fermented by \\ Aspergillus niger on Carcass of Weaning Rex Rabbit)
}

\author{
Syahril Bancin ${ }^{1}$, Hamdan $^{2}$ dan Nevy Diana Hanafi ${ }^{2}$ \\ 1. Mahasiswa Program Studi Peternakan Fakultas Pertanian Universitas Sumatera Utara \\ 2. Staf Pengajar Program Studi Peternakan Fakultas Pertanian Universitas Sumatera Utara
}

\begin{abstract}
Feed is an important factor in the livestock business, balanced nutrition will result in higher carcass production. The objective of this study was to measure the effectiveness of Physical Form of Rations Containing Cocoa Pod Fermented by Aspergillus niger on rabbit carcass. The experiment was conducted at the Compost Center Jl. Biotechnology University of Sumatera Utara. The study started from July to Sebtember 2012. Research method used randomized block design, treatment consisted of two factors: the physical properties of feed (mash and pellets) and fermented cocoa pod percentage (0\%, 5\%, and 10\%) with two blocks. Parameters observed body weight, carcass, carcass percentage and comersial slice (foreleg, rack, hindleg). The results showed that there is no interaction $(P>0,05)$ between physical feed and any levels cocoa pod fermentated. Physical feed and any levels cocoa pod fermentated even showed no significant different $(P>0,05)$ for all variables. It can be concluded that fermented pod cocoa can be used as feed of Rex rabbit.
\end{abstract}

Keywords: Carcass, Physical form rations, Pod cocoa, Aspergillus niger, Rex rabbit

\begin{abstract}
ABSTRAK
Pakan merupakan faktor penting dalam usaha peternakan kelinci. Nutrisi yang seimbang akan menghasilkan produksi karkas yang baik. Tujuan dari penelitian ini adalah untuk mengukur nilai keefektifan bentuk fisik ransum yang mengandung pod kakao (Theobroma cacao L,.) fermentasi (Aspergillus niger) terhadap karkas kelinci. Penelitian dilaksanakan di Compos Centre Jalan Bioteknologi Universitas Sumatera Utara, dimulai dari bulan Juli sampai Sebtember 2012. Metode penelitian yang digunakan adalah Rancangan Acak Kelompok Faktorial, perlakuan terdiri dari 2 faktor yaitu sifat fisik pakan (mash dan Pellet) dan persentase pod kakao fermentasi $(0 \%, 5 \%, 10 \%)$. Parameter penelitian adalah bobot potong, bobot karkas, persentase bobot karkas, dan irisan komersil (bobot kaki depan, bobot dada-leher, bobot pinggang dan bobot kaki belakang). Hasil penelitian menunjukkan dengan tidak terdapatnya interaksi $(\mathrm{P}>0,05)$ antara bentuk fisik ransum dan pemberian berbagai level pod kakao fermentasi. Bentuk fisik ransum dan pemberian berbagai level pod kakao fermentasi juga tidak menunjukkan pengaruh yang nyata $(\mathrm{P}>0,05)$ terhadap keseluruhan peubah. Dapat disimpulkan bahwa pod kakao fermentasi dapat digunakan sebagai pakan kelinci Rex.
\end{abstract}

Kata kunci: karkas, bentuk fisik ransum, Pod kakao, fermentasi, Aspergillus niger, Kelinci Rex

\section{PENDAHULUAN}

Seekor kelinci bisa menghasilkan daging 50-60 \% setiap kilogram bobot badan. Daging kelinci mengandung lemak dan kolesterol jauh lebih rendah dibanding dengan daging ayam, daging sapi, daging domba dan daging babi, tetapi kandungan proteinnya lebih tinggi. Kandungan lemak kelinci hanya sebesar 8\% sedangkan ayam 12\%, daging sapi 24\%, daging domba $14 \%$ dan daging babi $21 \%$. Kadar kolesterol daging kelinci sekitar 164 mg/100 gr, 
sedangkan daging ayam, daging sapi, daging domba dan daging babi berkisar 220-250 $\mathrm{mg} / 100$ gr daging. Kandungan protein daging kelinci mencapai 21\%, sementara ternak lain hanya 17-20\% (Masanto dan Agus, 2010).

Beternak kelinci sangat menguntungkan secara ekonomis. Dimana ternak kelinci ini merupakan salah satu ternak yang dapat melahirkan banyak anak pada setiap kelahirannya. Dengan menajemen pemeliharaan yang bagus ada kemungkinan ternak kelinci ini akan dapat membantu memasok kebutuhan akan daging di Indonesia. Salah satu menajemen pemeliharaan yang harus di perhatikan adalah pakan, di mana pakan merupakan salah satu faktor yang sangat penting. Syarat pakan yang baik adalah mudah didapat, disukai ternak dan yang paling terpenting adalah tidak bersaing dengan manusia. Salah satu pakan alternatif yang dapat digunakan dan tidak bersaing dengan manusia adalah pod kakao (Theobroma cacao L..). Pod kakao adalah kulit buah kakao yang merupakan hasil samping dari pengolahan paska panen kakao yang biasanya terbuang oleh si petani begitu saja di perkebunannya. Kondisi pod kakao memang kurang baik untuk dijadikan bahan baku pakan ternak karena berserat kasar yang tinggi dan mengandung anti nutrisi. Upaya meningkatkan kualitas pakan nilai gizi pakan hasil ikutan perkebunan yang berkualitas rendah merupakan upaya strategis dalam meningkatkan ketersediaan pakan (Laconi, 1998).

Berdasarkan uraian diatas maka layak untuk dilakukan penelitian terhadap pemanfaatan pod kakao yang difermentasi dengan Aspergillus niger pada pakan terhadap bobot potong, bobot karkas, persentase bobot karkas, bobot kaki depan, bobot dada-leher, bobot pinggang dan bobot kaki belakang pada ternak kelinci rex lepas sapih.

\section{BAHAN DAN METODE}

\section{Lokasi dan Waktu Penelitian}

Penelitian ini dilaksanakan di Compost Centre Jl. Bioteknologi Universitas Sumatera, Medan. Penelitian ini dilaksanakan selama 10 minggu dimulai dari tanggal 19 Juli 2012 sampai dengan 27 September 2012.

\section{Bahan dan Alat Penelitian}

Kelinci Rex jantan umur 8 minggu sebanyak 12 ekor dengan bobot $662-1153 \mathrm{~g}$ yang dikelompokkan dalam 2 kelompok yaitu: 662-902 g dan 903-1153 g. Pod kakao (Theobrama cacao L.), tepung jagung, tepung ikan, bungkil kedelai, bungkil kelapa, dedak, BIS, kapur, pod kakao fermentasi, top mix, minyak nabati sebagai bahan penyusun ransum 
kelinci selama 8 minggu, air minum, rumput kolonjono (panicum muticum), obat-obatan (wormectin, antibloat), vitamin (B-complex) dan rodalon sebagai desinfektan kandang.

Kandang individu dengan ukuran 50 x 50 x $50 \mathrm{~cm}$ sebanyak 12 petak. Pencetak pellet, timbangan bobot badan dengan kapasitas $15 \mathrm{~kg}$ dengan kepekaan $10 \mathrm{~g}$, timbangan ransum dengan kapasitas $2 \mathrm{~kg}$ dengan kepekaan $1 \mathrm{~g}$, tempat pakan dan tempat minum pada tiap kandang dengan total sebanyak 12 unit, mesin giling untuk membuat tepung, lampu 32 watt sebagai penerangan kandang, termometer untuk mengetahui suhu kandang, sapu lidi, kuas, sapu kecil sebagai alat pembersih kandang, talenan dan plastik transparan, terpal plastik sebagai alas untuk menyusun pellet, kardus sebagai tempat penyimpanan bahan untuk pellet. Komposisi susunan ransum kelinci selama penelitian tersaji pada Tabel 1.

Tabel 1. Komposisi susunan ransum

\begin{tabular}{llll}
\hline Bahan Pakan & \multicolumn{3}{c}{ Jumlah Bahan Pakan } \\
\cline { 2 - 4 } & P0 & P1 & P2 \\
\hline T. jagung & 42 & 40 & 39 \\
T. ikan & 10 & 10 & 9,5 \\
B. kedelai & 7 & 6,5 & 6 \\
B. kelapa & 3,5 & 3,5 & 3,5 \\
Dedak & 16,4 & 14,5 & 12,5 \\
Bis & 15,4 & 15 & 14 \\
Kapur & 0,5 & 0,5 & 0,5 \\
Pod kakao F & 0 & 5 & 10 \\
Top mix & 0,7 & 0,5 & 0,5 \\
M. nabati & 0,5 & 0,5 & 0,5 \\
Molasses & 4 & 4 & 4 \\
\hline Total & 100 & 100 & 100 \\
\hline Nutrisi & & & 2695,89 \\
\hline Energi Metabolik & 2760,36 & 2727,94 & 17,37 \\
Protein Kasar & 17,79 & 17,73 & 5,33 \\
Lemak Kasar & 5,8 & 5,59 & 7,53 \\
Serat Kasar & 6,18 & 6,9 & \\
\hline
\end{tabular}




\section{Skema pengolahan pod kakao fermentasi Aspergillus niger}

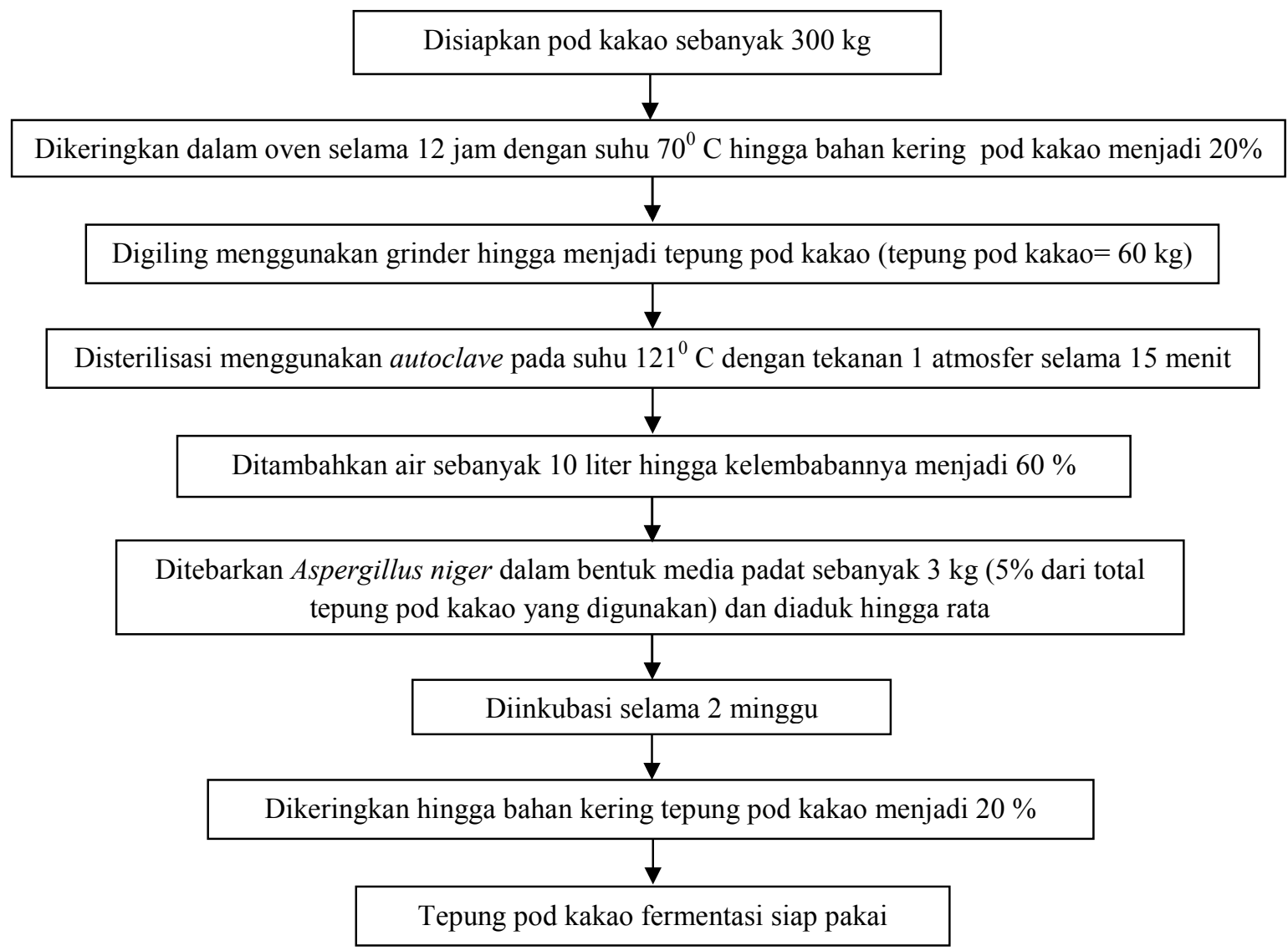

\section{Metode Penelitian}

Metode penelitian yang digunakan adalah Rancangan Acak Kelompok (RAK) faktorial yang terdiri dari 2 faktor yaitu:

Faktor A (bentuk fisik pakan) dengan 2 taraf: $\mathrm{SFP}_{1}$ : tepung/ mash

$$
\mathrm{SFP}_{2} \text { : pellet }
$$

Faktor B (persentase kakao) dengan 3 taraf : PK0: 0\% pod kakao fermentasi

$$
\begin{aligned}
& \mathrm{PK}_{1}: 5 \% \text { pod kakao fermentasi } \\
& \mathrm{PK}_{2}: 10 \% \text { pod kakao fermentasi }
\end{aligned}
$$

\section{Parameter Penelitian}

1. Bobot potong diperoleh dengan cara penimbangan bobot akhir kelinci setelah dipuasakan

2. Bobot karkas adalah bobot yang diperoleh dari hasil penimbangan dari daging bersama tulang kelinci yang telah dipisahkan dari kepala sampai batas pangkal leher dan dari kaki sampai batas pergelangan kaki, isi rongga perut, darah, ekor dan kulit 
3. Persentase bobot karkas diperoleh dengan cara membagikan bobot karkas dengan bobot potong dikali $100 \%$

4. Bobot kaki depan diperoleh dengan cara melepaskan pergelangan kaki dan pangkal paha yang dipotong dari batas lengan sampai pergelangan

5. Persentase bobot dada dan leher diperoleh dengan cara dipotong pada pangkal leher dan dipisahkan dari pinggang dengan membuat potongan antara tulang rusuk terahir

6. Persentase bobot kaki belakang diperoleh dengan cara dipotong pada sendi antara tulang batas pangkal paha hingga pergelangan.

\section{HASIL DAN PEMBAHASAN}

Hasil penelitian yang dilakukan selama 8 minggu terhadap bobot potong, bobot karkas, persentase bobot karkas, bobot kaki depan, bobot dada leher dan bobot kaki belakang dapat dilihat pada tabel rekapitulasi yang tertera pada Tabel 2.

Tabel 2. Rekapitulasi Hasil Penelitian

\begin{tabular}{|c|c|c|c|c|c|c|}
\hline Perlakuan & $\overline{\mathrm{BP}}$ & $\mathrm{BK}$ & $\% \mathrm{BK}$ & BKD & $\overline{B D L}$ & $\overline{B K B}$ \\
\hline SFP1PK0 & $1880,50^{\mathrm{tn}}$ & $999,50^{\mathrm{tn}}$ & $52,94^{\text {th }}$ & $150,50^{\mathrm{tn}}$ & $201,00^{\mathrm{tn}}$ & $300,50^{\mathrm{tn}}$ \\
\hline SFP1PK1 & $1923,50^{\operatorname{tn}}$ & $1042,50^{\operatorname{tn}}$ & $53,70^{\text {tn }}$ & $157,00^{\text {tn }}$ & $209,50^{\mathrm{tn}}$ & $313,50^{\mathrm{tn}}$ \\
\hline SFP1PK2 & $2000,50^{\text {tn }}$ & $1119,50^{\mathrm{tn}}$ & $55,85^{\text {tn }}$ & $169,00^{\text {tn }}$ & $225,00^{\text {tn }}$ & $337,00^{\text {tn }}$ \\
\hline SFP2PK0 & $1985,00^{\text {tn }}$ & $1104,00^{\mathrm{tn}}$ & $55,46^{\mathrm{tn}}$ & $166,50^{\text {tn }}$ & $222,00^{\mathrm{tn}}$ & $332,00^{\mathrm{tn}}$ \\
\hline SFP2PK1 & $2070,00^{\text {tn }}$ & $2378,00^{\text {tn }}$ & $57,36^{\text {tn }}$ & $179,00^{\text {tn }}$ & $238,50^{\mathrm{tn}}$ & $358,00^{\text {tn }}$ \\
\hline SFP2PK2 & $2014,00^{\operatorname{tn}}$ & $1097,00^{\text {tn }}$ & $54,41^{\text {tn }}$ & $170,50^{\text {tn }}$ & $227,50^{\operatorname{tn}}$ & $341,00^{\text {tn }}$ \\
\hline \multirow[t]{4}{*}{ Keterangan: } & \\
\hline & & \multicolumn{5}{|c|}{ tn $=$ tidak nyata } \\
\hline & \multicolumn{6}{|c|}{ - rersentase Douor } \\
\hline & BDL & Dada Leher & & Bob & ki Belakang & \\
\hline
\end{tabular}

\section{Bobot Potong}

Rataan bobot potong tertinggi selama penelitian ada pada perlakuan SPF2PK1 yaitu sebesar 2070,00 g dan yang terendah pada perlakuan SFP1PK0 yaitu sebesar 1880,50 g. Rataan bobot potong kelinci Rex yang diproleh antar perlakuan bervariasi yaitu pada perlakuan SFP1PK0 sebesar 1880,50 g, SFP1PK1 sebesar 1923,50 g, SFP1PK2 sebesar 2000,50 g, SFP2PK0 sebesar 1985,00 g, SFP2PK1 sebesar 2070,00 g, SFP2PK2 sebesar $2014,00 \mathrm{~g}$.

Bobot potong diperoleh dengan cara penimbangan bobot akhir kelinci setelah dipuasakan selama 10 jam. Berdasarkan Tabel 2 diatas terlihat bahwa bentuk fisik ransum dengan penambahan berbagai tingkat level pod kakao fermentasi tidak memberikan pengaruh 
yang nyata $(\mathrm{P}>0,05)$ terhadap bobot potong. Hal ini menunjukkan bahwa perlakuan pod kakao tidak perlu diberikan karena hasil penelitian tidak menunjukkan perbedaan yang nyata.

Hasil penlitian pada Tabel 2 diketahui bahwa tidak terdapatnya interaksi antara faktor A (bentuk fisik ransum) dan faktor B (persentase pod kakao fermentasi Aspergillus niger) akan tetapi faktor A dan faktor B saling memberikan pengaruh yang sangat nyata terhadap pertambahan bobot badan, hal ini juga berhubungan dengan bobot potong, yaitu semakin besar pertambahan bobot badan maka otomatis bobot potong juga akan semakin besar pula. Hal ini sesuai dengan pernyataan Muryanto dan Prawiradigdo (1993) dan Kartadisastra (1998) yang menyatakan bahwa semakin tinggi bobot potong maka semakin tinggi persentase bobot karkasnya. Hal ini disebabkan proporsi bagian-bagian tubuh yang menghasilkan daging akan bertambah selaras dengan ukuran bobot tubuh.

Hasil penelitian yang diperoleh pada penelitian ini lebih tinggi dari hasil penelitian Sianipar (2008) yang menggunakan objek kelinci jantan lokal selama 9 minggu penelitian dengan pemberian tepung keong mas, dimana rataan bobot potong yang tertinggi 1902,00 g dan yang terendah 1614,00 g, ini diakibatkan karena perbedaan jenis kelinci yang di pelihara dan selain itu juga pakan yang digunakan berbeda. Dimana pada penelitian ini menggunakan tepung pod kakao fermentasi dengan Aspergillus niger yang sangat membantu dalam menghasilkan bebrapa enzim salah satunya enzim selulase yang berguna untuk pemecahan selulosa.

Keefisienan tingkat konsumsi ransum sangat di pengaruhi oleh sifat fisik pakan. Ransum bentuk pellet lebih efisien dibandingkan dengan ransum berbentuk tepung. Hal ini didukung oleh pendapat Khalil (1999) yang menyatakan bahwa adapun kelebihan ransum berbentuk pellet adalah sebagai berikut: meningkatkan selera makan/palatabilitas, pemborosan ransum akibat tumpah/terbuang dapat ditekan, dapat mengefisienkan formula ransum, karena setiap butiran pellet mengandung nutrisi yang sama, ternak tidak diberi kesempatan untuk memilih-milih makanan yang disukai.

\section{Bobot Karkas dan Persentase Bobot Karkas}

Berdasarkan Tabel 2 tampak bahwa rataan bobot karkas tertinggi yang diperoleh dari hasil penelitian ada pada perlakuan SPF2PK1 yaitu sebesar $2378,00 \mathrm{~g}$ dan yang terendah pada perlakuan SFP1PK0 yaitu sebesar 999,50 g. Rataan bobot karkas kelinci Rex yang diperoleh antar perlakuan bervariasi yaitu pada perlakuan SFP1PK0 sebesar 999,50 g, SFP1PK1 sebesar 1042,50 g, SFP1PK2 sebesar 1119,50 g, SFP2PK0 sebesar 1104,00 g, SFP2PK1 sebesar 2378,00 g, SFP2PK2 sebesar 1097,00 g. 
Rataan persentase bobot karkas tertinggi selama penelitian terdapat pada perlakuan SPF2PK1 yaitu sebesar 57,36 \% dan yang terendah pada perlakuan SFP1PK0 yaitu sebesar $52,94 \%$. Rataan persentase bobot karkas kelinci Rex yang diproleh antar perlakuan bervariasi yaitu pada perlakuan SFP1PK0 sebesar 52,95\%, SFP1PK1 sebesar 53,70\%, SFP1PK2 sebesar 55,85 \%, SFP2PK0 sebesar 55,46\%, SFP2PK1 sebesar 57,36 \%, SFP2PK2 sebesar $54,41 \%$.

Hasil penelitian pada Tabel 2 di atas terlihat bahwa bentuk fisik ransum dengan penambahan berbagai tingkat level pod kakao fermentasi tidak memberikan pengaruh yang nyata $(\mathrm{P}>0,05)$ terhadap bobot karkas dan persentase bobot karkas. Hal ini menunjukkan bahwa perlakuan pod kakao tidak perlu diberikan karena hasil penelitian tidak menunjukkan perbedaan yang nyata.

Perlakuannya tidak nyata, ini disebabkan oleh bobot potong yang berbeda tidak nyata, sehingga dihasilkan bobot karkas yang tidak berbeda nyata pula. Hal ini didukung oleh pendapat Sarwono (2001) yang menyatakan bahwa besarnya bobot karkas tergantung besarnya kelinci yang akan dipotong. Meningkatnya bobot potong sejalan dengan meningkatnya bobot karkas pula. Hal ini juga di dukung oleh pernyataan Muryanto dan Prawirodigdo (1993) yang menyatakan bahwa semakin tinggi bobot potong maka semakin tinggi persentase bobot karkasnya. Hal ini disebabkan proporsi bagian-bagian tubuh yang menghasilkan daging akan bertambah selaras dengan ukuran bobot tubuh.

Besar persentase bobot karkas tersebut sangat tergantung pada besar tubuh kelinci, sistem pemeliharaan, kualitas bibit, macam dan kualitas pakan, kesehatan ternak dan perlakuan sebelum dipotong. Persentase karkas yang dihasilkan sangat tergantung pada besar tubuh kelinci, dan sebagai patokan, besar karkas kelinci yang baik seharusnya berkisar antara $40 \%-52 \%$ dari berat potongnya. Selain itu persentase karkas juga dipengaruhi oleh umur potong dan jenis kelamin (Soeparno, 1994).

Apabila dibandingkan dengan penelitian Girsang (2001) maka hasil yang diperoleh lebih tinggi, yaitu pada penelitian ini rataan yang diperoleh sebesar 1290,00 g sedangkan pada penelitian girsang sebesar 1089,00 g. Hal ini terjadi karena palatabilitas pod kakao fermentasi lebih tinggi dari pada keong mas yang memiliki aroma yang amis, sehingga mempengaruhi palatabilitas pada ternak. 


\section{Bobot Kaki Depan dan Bobot Kaki Belakang}

Berdasarkan Tabel 2 dapat dilihat rataan persentase bobot kaki depan tertinggi selama penelitian ada pada perlakuan SPF2PK1 yaitu sebesar 179,00 g dan yang terendah pada perlakuan SFP1PK0 yaitu sebesar 150,50 g. Rataan bobot kaki depan kelinci Rex yang diperoleh antar perlakuan bervariasi yaitu pada perlakuan SFP1PK0 sebesar 150,50 g, SFP1PK1 sebesar 157,00 g, SFP1PK2 sebesar 169,00 g, SFP2PK0 sebesar 166,50 g, SFP2PK1 sebesar 179,00 g, SFP2PK2 sebesar 170,50 g.

Bobot kaki belakang tertinggi selama penelitian ada pada perlakuan SPF2PK1 yaitu sebesar 358,00 g dan yang terendah pada perlakuan SFP1PK0 yaitu sebesar 300,50 g. Rataan bobot kaki belakang kelinci Rex yang diperoleh antar perlakuan bervariasi yaitu pada perlakuan SFP1PK0 sebesar 300,50 g, SFP1PK1 sebesar 313,50 g, SFP1PK2 sebesar 337,00 g, SFP2PK0 sebesar 332,00 g, SFP2PK1 sebesar 358,00 g, SFP2PK2 sebesar 341,00 g.

Tabel 2 menunjukkan bahwa bentuk fisik ransum dengan penambahan berbagai tingkat level pod kakao fermentasi tidak memberikan pengaruh yang nyata $(\mathrm{P}>0,05)$ terhadap bobot kaki depan dan bobot kaki belakang. Hal ini menunjukkan bahwa perlakuan pod kakao tidak perlu diberikan karena hasil penelitian tidak menunjukkan perbedaan yang nyata. Perlakuannya tidak nyata, ini disebabkan oleh bobot potong yang berbeda tidak nyata, sehingga diperoleh bobot kaki depan dan bobot kaki belakang yang tidak berbeda nyata pula. Semakain besar bobot potong maka semakin besar pula bobot komersial. Hal ini disebabkan proporsi bagian-bagian tubuh yang menghasilkan daging akan bertambah selaras dengan ukuran bobot tubuh. Pernyataan ini sesuai dengan pendapat Herman dan Sugana (1983) yang menyatakan bahwa potongan komersial kelinci sangat dipengaruhi oleh bobot potongnya.

\section{Bobot Dada Leher}

Rataan bobot dada leher tertinggi selama penelitian (Tabel 2) ada pada perlakuan SPF2PK1 yaitu sebesar 238,50 g dan yang terendah pada perlakuan SFP1PK0 yaitu sebesar 201,00 g. Rataan bobot dada leher kelinci Rex yang diperoleh antar perlakuan bervariasi yaitu pada perlakuan SFP1PK0 sebesar 201,00 g, SFP1PK1 sebesar 209,50 g, SFP1PK2 sebesar 225,50 g, SFP2PK0 sebesar 222,00 g, SFP2PK1 sebesar 238,50 g, SFP2PK2 sebesar $227,50 \mathrm{~g}$.

Berdasarkan Tabel 2 di atas terlihat bahwa bntuk fisik ransum dengan penambahan berbagai tingkat level pod kakao fermentasi tidak memberikan pengaruh yang nyata terhadap bobot dada leher. Hal ini menunjukkan bahwa perlakuan pod kakao tidak perlu diberikan karena hasil penelitian tidak menunjukkan perbedaan yang nyata. 
Perlakuannya tidak nyata, ini disebabkan oleh bobot potong yang berbeda tidak nyata, sehingga diperoleh bobot dada leher yang tidak berbeda nyata pula. Semakain besar bobot potong maka semakin besar pula bobot komersial. Hal ini disebabkan proporsi bagian-bagian tubuh yang menghasilkan daging akan bertambah selaras dengan ukuran bobot tubuh. Pernyataan ini sesuai dengan pendapat Herman dan Sugana (1983) yang menyatakan bahwa potongan komersial kelinci sangat dipengaruhi oleh bobot potongnya.

\section{KESIMPULAN}

Pengaruh bentuk fisik ransum dengan penambahan berbagai level pod kakao fermentasi memberikan pengaruh yang tidak nyata terhadap bobot potong, bobot karkas, persentase bobot karkas, dan juga irisan komersil (bobot kaki depan, bobot dada leher, bobot kaki belakang) pada penelitian ini.

\section{DAFTAR PUSTAKA}

Girsang, D.P., 2001. Pengaruh Pemberian Berbagai Level Tepung Keong Mas Terhadap Karkas Kelinci Jantan Lokal Umur 16 Minggu. Jurusan Peternakan Fakultas Pertanian Universitas Sumatera Utara Medan.

Herman, R. M. Duldjaman dan N. Sugana., 1983. Irisan Komersil Karkas Kelinci dan Proporsi Dagingnya. Media Peternakan.

Khalil., 1999. Pengaruh Kandungan Air dan Ukuran Partikel Terhadap Sifat Fisik Pakan: Kerapatan Tumpukan, Kerapatan Pemadatan Tumpukan dan Berat Jenis. Media Peternakan 22 (1): 1-11.

Kartadisastra, H. R., 1998. Ternak Kelinci dan Teknologi Pasca Panen. Kanisius, Yogyakarta.

Laconi, E. B., 1998. Peningkatan Kualitas Kakao Melalui Amoniasi Dengan Urea dan Biofermentasi Dengan Phanerochaete Chrysosporium serta Penjabarannya Dalam

Formula Ransum Ruminansia. Disertasi. Program Pacasarjana institut Pertanian Bogor, bogor.

Masanto, R dan Agus., A. 2010. Beternak Kelinci Podong. Penebar Swadaya. Jakarta.

Sianipar, M.E., 2008. Pemanfaatan Tepung Keong Mas Sebagai Subtitusi Tepung Ikan

Dalam Ransum Terhadap Karkas Kelinci Jantan. Jurusan Peternakan Fakultas Pertanian Universitas Sumatera Utara Medan.

Muryanto dan S. Prawirodigdo., 1993. Pengaruh Jenis Kelamin dan Bobot Potong Terhadap Persentase Karkas dan Non-karkas Pada Kelinci Rex. Jurnal Ilmiah Penelitian Ternak Klepu 1:33-38.

Sarwono, B., 2001.Kelinci Potong dan Hias. Agromedia Pustaka, Jakarta

Soeparno, 1994. Ilmu dan teknologi daging. Gadjah Mada University Press, Yogyakarta. 